\title{
TRANSBORDER ASSOCIATIONS OF TERRESTRIAL ISOPODS (CRUSTACEA, ISOPODA, ONISCIDEA) OF MEXICO AND THE UNITED STATES
}

\author{
Joan P. Jass ${ }^{1}$ and Barbara R. Klausmeier ${ }^{1}$
}

Key words: terrestrial isopods, Oniscidea, Mexico, United States, zoogeography.

Hatch (1947) broadly characterized natural habitats of native North American terrestrial isopods as being either littoral or cave-dwelling, with few exceptions. The habitat analysis of Jass and Klausmeier (2000) generally confirmed this characterization. Immigrant rather than native species comprised the vast majority of terrestrial isopods $(43.2 \%)$ whose major habitat preference was not a cave or littoral habitat. The origins of these habitat preferences can be traced to the evolutionary history of the Oniscidea. In contrast to many other modern terrestrial taxa, oniscidean isopods are assumed to be directly descended from marine ancestors rather than freshwater intermediaries. Range expansion away from coastal habitats by those ancestral terrestrial isopods is hypothesized to have required a tropical era in North America in Tertiary times (Vandel 1960). Subsequent major changes of climate to less favorable conditions would have left the inland descendants of these cryptosphere-limited crustaceans (Savory 1971) isolated in humid, constant-temperature habitats (e.g., caves).

In terms of their paleohistory, endemic American oniscideans are hypothesized to have originated in warm, tropical regions of the hemisphere. The decisive summary statement of Van Name (1936: 22) regarding regional distribution was as follows: "It is only from the southern boundary of the United States southward that we begin to find a land isopod fauna well developed." Van Name's (1936) corollary hypothesis was that the presence of a welldeveloped fauna to the south may have been a source of much of the fauna further north. These speculations placed an unusual emphasis on the Mexico-United States (U.S.) border as a demarcating line of possible zoogeographic significance for oniscideans. Yet, when Van
Name's American monograph was published, only 15 species had been reported from Mexico, offering a relatively meager basis for making such comparisons.

Subsequent research on the Mexican fauna has increased significantly the number of species known to occur there. Beginning in 1950, and for well over a decade thereafter, E. Rioja of the National Autonomous University of Mexico published a series of papers in the annals of the university's Institute of Biology, which included numerous new species descriptions. Also, a major monographic treatment of the country's terrestrial isopods was the unpublished dissertation of University of Utah researcher S.B. Mulaik (Mulaik 1954). F. Bonet, an expert on the Mexican cave fauna, cooperated with Mulaik to produce a Spanish translation (Mulaik 1960) wherein many new species were described and illustrated, new state records were documented, and a bibliographic compilation of the older literature was given.

Two companion atlases (Jass and Klausmeier 2001, 2004) updating the distribution records from the U.S. and Mexico facilitate a reexamination of the transborder associations between the 2 faunas. The terrestrial members of Isopoda (all belonging to the suborder Oniscidea) have 86 representative species, 23 genera, and 16 families in Mexico and 107 species, 40 genera, and 17 families in the U.S. For Mexico, 62.8\% of the species recorded have their type localities in that country. A roughly similar percentage $(66.1 \%)$ of the American species north of Mexico are endemics (Jass and Klausmeier 2000).

We compared oniscidean faunal characteristics across the Mexico-U.S. boundary by calculating coefficients of faunal similarity (Cox

${ }^{1}$ Department of Invertebrate Zoology, Milwaukee Public Museum, Milwaukee, WI 53233. 
and Moore 1985), $(100 \cdot \mathrm{C}) / \mathrm{N}_{1}$, in which $\mathrm{C}$ is the number of species (genera or families) in common to the 2 divisions being compared and $\mathrm{N}_{1}$ is the number of species (genera or families) in the division having the smaller fauna. For example, the coefficient for species from Mexico versus the U.S. was calculated as $(100 \cdot 29) / 86)$, giving a result of $33.7 \%$. The country-to-country faunal similarity indices were $33.7 \%$ for species, $69.7 \%$ for genera, and $87.5 \%$ for families.

This similarity index (Cox and Moore 1985) was also used in making calculations for a more narrow comparison between the faunas from the 2 sets of bordering states that meet at the Mexico-U.S. boundary. This grouping of states in Mexico includes (east to west) Tamaulipas, Nuevo Leon, Coahuila, Chihuahua, Sonora, and Baja. (Because many sources in the literature reviewed did not separate Baja California into separate northern and southern entities, Jass and Klausmeier [2004] reported those 2 states as 1.) In the U.S. the corresponding grouping of states includes Texas, New Mexico, Arizona, and California. The resulting region-to-region similarity indices are compared to those for the corresponding country-to-country figures in Table 1.

To evaluate the degrees of similarity revealed by our use of the Cox and Moore (1985) coefficients, we compared their findings with ours. They used the index to make comparisons at the family level between the Triassic vertebrate faunas of today's continents and found values ranging from $40.0 \%$ (Asia-North America) up to $90.0 \%$ (Asia-India). As expected, our Mexico-U.S. family-level comparison for oniscideans closely matches $(87.5 \%)$ the highest similarity figure of Cox and Moore (1985); the even higher result for the comparison between sets of bordering states matches it exactly.

The lowest figure in our results is the countrywide comparison between Mexico and the U.S. at the species level $(33.7 \%)$. This is not unexpected, given the additional sources of faunal diversity present when the entirety of each of these 2 vast countries is considered in the expression of faunal similarity. But in contrast, the fact that the species-level comparison between the 2 groups of bordering states was more than 20 percentage points higher $(54.5 \%)$ than the country-to-country comparison indicates that there are significant cross-
TABLE 1. Indices of faunal similarity in species, genera, and families across boundaries at 2 levels: the country-tocountry (Mexico versus U.S.) level compared to the region-to-region (Mexican border states versus U.S. border states) level.

\begin{tabular}{lcc}
\hline $\begin{array}{l}\text { Taxonomic } \\
\text { level }\end{array}$ & Mexico-U.S. & $\begin{array}{c}\text { Baja to Tamaulipas- } \\
\text { California to Texas }\end{array}$ \\
\hline Species & $33.7 \%$ & $54.5 \%$ \\
Genera & $69.7 \%$ & $76.9 \%$ \\
Families & $87.5 \%$ & $90.0 \%$ \\
\hline
\end{tabular}

border affinities in the regions where Mexico and the U.S. meet. The genus-level comparison for these states was also relatively high.

To compare these 2 faunas further on an ecological basis, we used the species-characteristic habitat data from Jass and Klausmeier (2000). Twelve oniscideans have records from both the Mexican and the U.S. states along the international border, $5(41.7 \%)$ of which are from coastal habitats (Ligia, 3 spp.; Littorophiloscia, 1 sp.; and Tylos, 1 sp.). Coastal occurrence is in fact the most common ecological affinity among the 12 . When regional studies have been done elsewhere, it has been possible to characterize in more detail the differences in ecological preferences of members of these genera. For example, in Bermuda, Tylos spp. were more likely to be collected within the area of tidal flux than Ligia spp., which occupied a drier zone ranging to the upper beach (Schultz 1972). Habitat data gathered in other geographic areas need confirmation by similar detailed comparative studies along Mexican-U.S. coastlines. We lack those studies at present but can generalize that the commonly reported affinity of terrestrial isopods in these 3 genera to coastal habitats identifies them as the littoral component of the fauna (sensu Hatch [1947]). This preliminary ecological analysis offers support for the early views of Van Name (1936) that the littoral habitat has a primary significance to terrestrial-isopod zoogeography and that it is key to understanding the patterns of distribution shown by a large portion of oniscidean species.

No other habitat factor is shared by the remainder of the 12 transborder species. While Van Name (1936) stated that the littoral connection constituted a direct explanation for 1 major class of American distributional patterns; he saw the problems of origin and distribution 
for the remaining terrestrial isopods, the nonlittoral species, as being more difficult and complicated.

Mulaik's monograph (1960) laid important groundwork in its pioneering attempt to summarize the Mexican fauna. However, we still lack data to test Van Name's (1936) underlying hypotheses regarding the origins of the present-day American fauna, which he regarded as survivors of a much larger group that had passed its maximum, leaving only terminal parts of some of its phylogenetic branches. While our preliminary analyses do not fulfill Van Name's (1936) high expectations for research that would elucidate this evolutionary history, they do provide some support for earlier statements regarding Mexican-United States transborder affinities of various components of this fauna.

\section{Literature Cited}

Cox, C.B., AND P.D. Mooke. 1985. Biogeography, an ecological and evolutionary approach. 4th edition. Blackwell, London.

HАтсH, M.H. 1947. The Chelifera and Isopoda of Washington and adjacent regions. University of Washington Publications in Biology 10:159-235.
Jass, J., and B. Klausmeier. 2000. Endemics and immigrants: North American terrestrial isopods (Isopoda, Oniscidea) north of Mexico. Crustaceana 73:771-799. . 2001. Terrestrial isopod (Crustacea: Isopoda) atlas for Canada, Alaska, and the contiguous United States. Milwaukee Public Museum Contributions in Biology and Geology 95:1-105.

. 2004. Terrestrial isopod (Crustacea: Isopoda) atlas for Mexico. Milwaukee Public Museum Contributions in Biology and Geology 100:1-77.

Mulaik, S. 1960. Contribucion al conocimiento de los isopodos terrestres de Mexico (Isopoda, Oniscoidea). Revista de la Sociedad Mexicana de Historia Natural 21:79-[292].

MulaIK, S.B. 1954. The origin, phylogeny, and systematics of Mexican terrestrial Isopoda (Crustacea, Oniscoidea). Doctoral dissertation, University of Utah, Salt Lake City.

SAVORY, T. 1971. Biology of the cryptozoa. Merrow, Durham, England.

Schultz, G. 1972. Ecology and systematics of terrestrial isopod crustaceans from Bermuda (Oniscoidea). Crustaceana 3:[79]-99.

VANDEL, A. 1960. Isopodes terrestres (premiere partie). Faune de France 64:1-416.

Van Name, W.G. 1936. The American land and fresh-water isopod Crustacea. Bulletin of the American Museum of Natural History 71:1-535.

Received 22 February 2005 Accepted 23 June 2005 